\title{
Downregulation of Activating Transcription Factor 5 Is Required for Differentiation of Neural Progenitor Cells into Astrocytes
}

\author{
James M. Angelastro, ${ }^{1 \star}$ Jeffrey L. Mason, ${ }^{1,2 \star}$ Tatyana N. Ignatova, ${ }^{3}$ Valery G. Kukekov, ${ }^{3}$ George B. Stengren, ${ }^{1}$ \\ James E. Goldman, ${ }^{1}$ and Lloyd A. Greene ${ }^{1}$ \\ ${ }^{1}$ Department of Pathology and Center for Neurobiology and Behavior, Columbia University College of Physicians and Surgeons, New York, New York 10032, \\ ${ }^{2}$ Farber Institute for Neuroscience, Thomas Jefferson University, Philadelphia, Pennsylvania 19107, and ${ }^{3}$ Departments of Neuroscience and Neurosurgery, \\ McKnight Brain Institute, Shands Cancer Center, University of Florida, Gainesville, Florida 32610
}

The mechanisms that regulate neural progenitor cell differentiation are primarily unknown. The transcription factor activating transcription factor 5 (ATF5) is expressed in neural progenitors of developing brain but is absent from mature astrocytes and neurons. Here, we demonstrate that ATF5 regulates the conversion of ventricular zone (VZ) and subventricular zone (SVZ) neural progenitors into astrocytes. Constitutive ATF5 expression maintains neural progenitor cell proliferation and blocks their in vitro and in vivo differentiation into astrocytes. Conversely, loss of ATF5 function promotes cell-cycle exit and allows astrocytic differentiation in vitro and in vivo. CNTF, a promoter of astrocytic differentiation, downregulates endogenous ATF5, whereas constitutively expressed ATF5 suppresses CNTF-promoted astrocyte genesis. Unexpectedly, constitutive ATF5 expression in neonatal SVZ cells both in vitro and in vivo causes them to acquire properties and anatomic distributions of VZ cells. These findings identify ATF5 as a key regulator of astrocyte formation and potentially of the VZ to SVZ transition.

Key words: ATF5; neural progenitor cells; CNTF; astrocyte; ventricular zone; neuron

\section{Introduction}

The transition of neural progenitor cells into neurons and glia is regulated in part by extrinsic signals that in turn act via target genes to either promote or repress differentiation programs (Gage, 2000; Kintner, 2002; Schuurmans and Guillemot, 2002; Arlotta et al., 2003). Here, we explore the role of one such key gene, activating transcription factor 5 (ATF5), in regulating differentiation of prenatal and postnatal neural progenitors into astrocytes.

ATF5 is a member of the activating transcription factor/cAMP response element-binding protein family. By means of a serial analysis of gene expression profiling study, we established that ATF5 transcripts are expressed highly in PC12 pheochromocytoma cells and are downregulated when such cells undergo NGFpromoted neuronal differentiation (Angelastro et al., 2000). NGF-stimulated downregulation also occurs at the protein level and with a time course inverse to that of neurite outgrowth (Angelastro et al., 2003). Moreover, constitutive expression of ATF5

\footnotetext{
Received Aug. 20, 2004; revised March 4, 2005; accepted March 4, 2005.

This work was supported in part by grants from the National Institutes of Health-National Institute of Neurological Disorders and Stroke (L.A.G. and J.E.G.) and the National Multiple Sclerosis Society (J.L.M.). G.B.S. was supported by grants from the Columbia University Summer Research Program for Science Teachers. We thank Claudine Bitel for superb technical assistance and Dr. Dennis Steindler for helpful discussions.

*J.M.A. and J.L.M. contributed equally to this work.

Correspondence should be addressed to James M. Angelastro, School of Veterinary Medicine, Department of Molecular Biosciences, University of California, Davis, CA 95616. E-mail: jmangelastro@ucdavis.edu. DOI:10.1523/JNEUROSCI.3447-04.2005

Copyright $\odot 2005$ Society for Neuroscience $\quad$ 0270-6474/05/253889-11\$15.00/0
}

in PC12 cells blocks their differentiative response to NGF, whereas an ATF5 dominant-negative form accelerates NGFstimulated neuronal differentiation.

ATF5 is expressed highly in the prenatal rodent brain ventricular zone (VZ) and is lost from VZ cells when they differentiate into postmitotic neurons (Angelastro et al., 2003). Constitutive expression of ATF5 blocks neuronal differentiation of cultured embryonic neural progenitor cells and maintains them in a proliferating state. Constitutively expressed ATF5 also blocks neurotrophin 3 (NT3)-promoted neuronal differentiation of cultured neural progenitors, whereas NT3 treatment of such cells both promotes their differentiation and downregulates endogenous ATF5 expression. Finally, loss of ATF5 function or expression leads to neuronal differentiation of cultured neural progenitors. These findings support a model in which ATF5 blocks neuronal differentiation of progenitor cells and maintains them in a proliferating, undifferentiated state. Neuronal differentiation thus requires downregulation of ATF5 by extrinsic factors such as NGF and NT3.

We also noted that ATF5 is expressed highly in clonal neurosphere cultures (Angelastro et al., 2003). Because such cells have the potential to differentiate into glia as well as neurons (Kukekov et al., 1999; Laywell et al., 1999), and because the embryonic VZ generates astrocytes in addition to neurons (Mehler, 2002; Noctor et al., 2002; Jacobsen and Miller, 2003), we considered the possibility that ATF5 also regulates gliogenesis. Therefore, we sought to address several key questions regarding the potential 
role of ATF5 in astrocyte development. First, does ATF5 influence the conversion of $\mathrm{VZ}$ neuroprogenitors into astrocytes as it does in the case of neurons? Does ATF5 loss of function only permit a neuronal fate, or does it also permit astrocytic differentiation? Second, because astrocytes primarily are generated postnatally from subventricular zone (SVZ) cells, do the latter express ATF5, and does ATF5 play a role in their differentiation? Third, do the effects of ATF5 constitutive expression and loss of function that are observed in vitro also pertain in vivo? Finally, what would be the in vivo consequences of manipulating ATF5 expression or activity on behavior of the affected cells? Would progenitor cells undergoing premature loss of ATF5 function show normal integration into the developing brain? Would sustained constitutive ATF5 expression alter the fate or properties of progenitor cells?

\section{Materials and Methods}

Reagents. Cell-culture medium DMEM, molecular biology reagents, and Lipofectamine 2000 were from Invitrogen (San Diego, CA). Fetal bovine serum was from JRH Biosciences (Lenexa, KS). 5'-Bromo-2'deoxyuridine (BrdU), FGF2, epidermal growth factor (EGF), CNTF, and anti-green fluorescent protein (GFP) IgG $_{1}$ were from Sigma (St. Louis, $\mathrm{MO}$ ). Biotinylated goat anti-mouse $\operatorname{IgG}_{1}$ and anti-mouse $\mathrm{IgG}_{2 \mathrm{a}}$ antibodies were from Southern Biotech (Birmingham, AL). Goat anti-mouse Alexa 488 and Alexa 568, goat anti-mouse $\operatorname{IgG}_{2 a}$ Alexa 488, goat antimouse IgG 1 Alexa 568, goat anti-rabbit Alexa 488 and 568, and mouse $\mathrm{IgG}_{2 \mathrm{a}}$ anti-GFP antibody were from Molecular Probes (Eugene, OR). Rabbit anti-GFP antibody was from BD Biosciences (Franklin Lake, NJ). Rat-401 IgG $\mathrm{I}_{1}$ anti-nestin antibody was from the Developmental Studies Hybridoma Bank (University of Iowa, Iowa City, IA) antibody collection. Mouse $\operatorname{IgG}_{2 \mathrm{a}}$ anti-tubulin $\beta$ (III) (TUJ1) was from Covance (Princeton, NJ). Rabbit anti-GFAP was from Dako (High Wycombe, UK), and mouse IgG $\mathrm{G}_{1}$ anti-GFAP antibody was from Chemicon (Temecula, CA). Mouse anti-polysialic acid-neural cell adhesion molecule (PSA-NCAM) antibody was a kind gift from Dr. Jane Dodd (Columbia University). Mouse anti- $\beta$-catenin was from Signal Transduction (Newington, $\mathrm{NH}$ ), and rabbit anti-Ki67 was from Novacastra (Burlingame, CA). Normal 10\% goat serum was from Zymed (San Francisco, CA).

Cell culture. Dissociated cultures of telencephalic cells were prepared from embryonic day 15 (E15) Sprague Dawley rats as described previously (Angelastro et al., 2003). Briefly, dissociated cultures of telencephalic cells were prepared from E15 Sprague Dawley rats. The outer epidermal layer was peeled from the head of the embryo. The telencephalon was then excised, and telencephalic tissue from two litters was placed in trypsin $(0.05 \%$ in $0.53 \mathrm{~mm}$ EDTA; Invitrogen) for $30 \mathrm{~min}$ (Li et al., 1998). The dissociated cells were centrifuged and resuspended in DMEM containing $5 \%$ FBS with or without $10 \mathrm{ng} / \mathrm{ml} \mathrm{EGF}$ and $20 \mathrm{ng} / \mathrm{ml}$ basic fibroblast growth factor and were plated on 24-well dishes coated with poly-L-lysine at 3-5 × $10^{5}$ cells per well (Laywell et al., 1999). Retrovirus $\left(\sim 1 \times 10^{6}\right.$ virus particles per $\left.\mathrm{ml}\right)$ was added at $5 \mu \mathrm{l}$ per well to infect the telencephalic cells $1 \mathrm{~d}$ after plating. The cultures were refed every $3 \mathrm{~d}$. The cells were fixed and examined $11 \mathrm{~d}$ later.

Adherent clonal neurosphere cultures were prepared from newborn mouse subependymal zone cells as described previously (Kukekov et al., 1997, 1999) with some modifications. Briefly, the minced brains of newborn mice were dissociated in $0.25 \%$ trypsin solution with $0.1 \mathrm{~mm}$ EDTA during slow stirring on a magnetic plate at room temperature for $15 \mathrm{~min}$. After trituration through a plastic $5 \mathrm{ml}$ pipette and a fire-polished Pasteur pipette, the dissociate was filtered through sterile gauze, washed three to five times in $5 \mathrm{ml}$ of DMEM/F12 medium to eliminate cell aggregates and debris, and then verified visually to contain only single cells when counted with a hemocytometer. Finally, cells were resuspended in methyl cellulose $(0.8 \%)$ in DMEM/F12 mixture (1:1) medium (Stem Cells Technologies, Vancouver, British Columbia, Canada) with insulin $(0.5 \mu \mathrm{g} /$ $\mathrm{ml})$, progesterone $(20 \mathrm{nM})$, putrescine $(100 \mu \mathrm{g} / \mathrm{ml})$, sodium selenite (30 $\mathrm{ng} / \mathrm{ml})$, and transferrin $(25 \mu \mathrm{g} / \mathrm{ml})$. The cells were seeded in six-well plates (Corning, Corning, NY) that were coated with a nonadhesive substrate, poly 2-hydroxyethyl methacrylate (Sigma), as recommended by the manufacturer, at a density of $5 \times 10^{4}$ cells per well. Freshly thawed EGF and FGF2 were added every $3 \mathrm{~d}$ during a $14-18 \mathrm{~d}$ period of clone generation to a concentration of $10 \mathrm{ng} / \mathrm{ml}$ each. Neurosphere cultures were maintained in a $37^{\circ} \mathrm{C}$ incubator with $5 \% \mathrm{CO}_{2}$ and $100 \%$ humidity. After clone formation, the clones were transferred to coverslips coated sequentially with poly-L-ornithine and laminin to allow the clones to attach and differentiate in DMEM/F12 medium with 10\% FCS.

PSA-NCAM + SVZ cells were prepared by immunopanning as described previously (Mason and Goldman, 2002). Briefly, the SVZ was removed from the brain of a 2-d-old Sprague Dawley rat and was mechanically and enzymatically dissociated with $0.125 \%$ trypsin (Sigma) and $0.02 \%$ collagenase (Worthington, Freehold, NJ). This cellular suspension was filtered through sterile $0.74 \mathrm{~mm}$ mesh, and the trypsin was neutralized with $10 \%$ heat-inactivated serum. The dissociated cells were collected by centrifugation and resuspended in $0.9 \mathrm{M}$ sucrose/MEM (Invitrogen). This cellular suspension was centrifuged again, and the progenitors (bottom layer) were collected and resuspended in serum-free medium (see below). Approximately $3.1 \times 10^{7}$ cells (range, $2.5 \times 10^{7}$ $4.1 \times 10^{7}$ cells) were isolated from the SVZ of each neonatal rat with the cells being pooled from five to six rat forebrains for each culture experiment. PSA-NCAM+ cells were purified from the total progenitors to $>98 \%$ purity (the range is between 96 and $99 \%$ ) by immunopanning as described previously (Mason and Goldman, 2002). In brief, immunopan plates were produced by incubating goat anti-mouse IgM antibody ( 20 $\mathrm{mg} / \mathrm{ml}$; Cappel, West Chester, PA), diluted in $50 \mathrm{~mm}$ Tris, in Falcon 1007 Petri dishes (Fisher Scientific, Houston, TX) overnight at $37^{\circ} \mathrm{C}$. The plates were then washed, incubated with PSA-NCAM hybridoma supernatant (undiluted) at $37^{\circ} \mathrm{C}$ for $3 \mathrm{~h}$, and then blocked with $10 \%$ normal goat serum $/ 10 \% \mathrm{BSA}$ at $37^{\circ} \mathrm{C}$ for $30 \mathrm{~min}$. Cells at $2 \times 10^{6}$ were then incubated in the PSA-NCAM immunoplate for $1 \mathrm{~h}$ at $37^{\circ} \mathrm{C}$. The plates were then washed and coated with trypsin/EDTA for $10 \mathrm{~min}$ at $37^{\circ} \mathrm{C}$. The detached cells were collected in an equal volume of $10 \%$ heat-inactivated serum to neutralize the trypsin, centrifuged, and then resuspended in serum-free medium. Some of the cells were then fixed and prepared for immunohistochemistry $1 \mathrm{~h}$ after isolation to determine purity. Approximately $4.1 \times 10^{4}$ PSA-NCAM + cells (range, $2.4 \times 10^{4}-6.9 \times 10^{4}$ PSA$\mathrm{NCAM}+$ cells) were isolated from each neonatal forebrain.

Transfection. The transfection of telencephalic cells was performed as described previously (Angelastro et al., 2003). Briefly, 80 pmol per well ATF5 small interfering RNA (siRNA) oligoduplex (AAN 19 ; AAG UCA GCU GCU CUC AGG UAC) was mixed with $1 \mu \mathrm{g}$ per well pCMS (immediate early cytomegavirus promoter; multiple cloning site, simian virus 40 promoter)-enhanced GFP (eGFP) vector in $100 \mu$ l of DMEM medium. An equal amount of DMEM medium premixed with $1 \mu \mathrm{l}$ of Lipofectamine 2000 per well was added and mixed with the vector and siRNA. After $30 \mathrm{~min}$, the final mixture was added to one-sixth of the final volume containing the cells, and the cells were refed with fresh culture medium after $7 \mathrm{~h}$ of transfection. As a control, telencephalic cells with transfected with pCMS-eGFP vector alone.

Retrovirus production and infection. A nonreplicating retrovirus expressing only eGFP was produced by transfecting subconfluent GP2 (293 cell retrovirus packaging line with $g a g$ and pol retrovirus genes) 293 cells with $15 \mu \mathrm{g}$ of QCX (Q series retrovirus vector, immediate early cytomegavirus promoter; $\mathrm{X}$ multiple cloning site for gene of interest)-eGFP or pLeGFP and $15 \mu \mathrm{g}$ of pVSV-G in presence of $10-20 \mu \mathrm{l}$ of Lipofectamine 2000 for $5 \mathrm{~h}$ (following the manufacturer's protocol; Clontech, Cambridge, UK). Alternatively, eGFP-only retrovirus was produced by centrifuging supernatant of a subconfluent cell line (transiently transfected with pVSV-G) that stably expresses eGFP in the tetracycline operon enhancer-promoter construct pNIT-eGFP (a gift from Drs. Theo Palmer, Steve Suhr, and Fred Gage, The Salk Institute, La Jolla, CA) (Palmer et al., 1999). GP2 293 cells were transfected as above with QCFLAG-ATF5-eGFP or pLeGFP-FLAG-NTAzip-ATF5 to produce the bicistronic FLAG-ATF5-eGFP or fusion eGFP-FLAG-NTAzip-ATF5 retroviruses. For telencephalic cells and for in vivo experiments, culture medium was collected $48 \mathrm{~h}$ after transfection, and the virus was concentrated by centrifugation at $50,000 \times g$ at $4^{\circ} \mathrm{C}$. The final titer was $\sim 1 \times 10^{6}$ virus particles per ml. Telencephalic cells were infected with $5 \mu \mathrm{l}$ of retrovirus per well $1 \mathrm{~d}$ after plating, and the cells were fixed and examined 

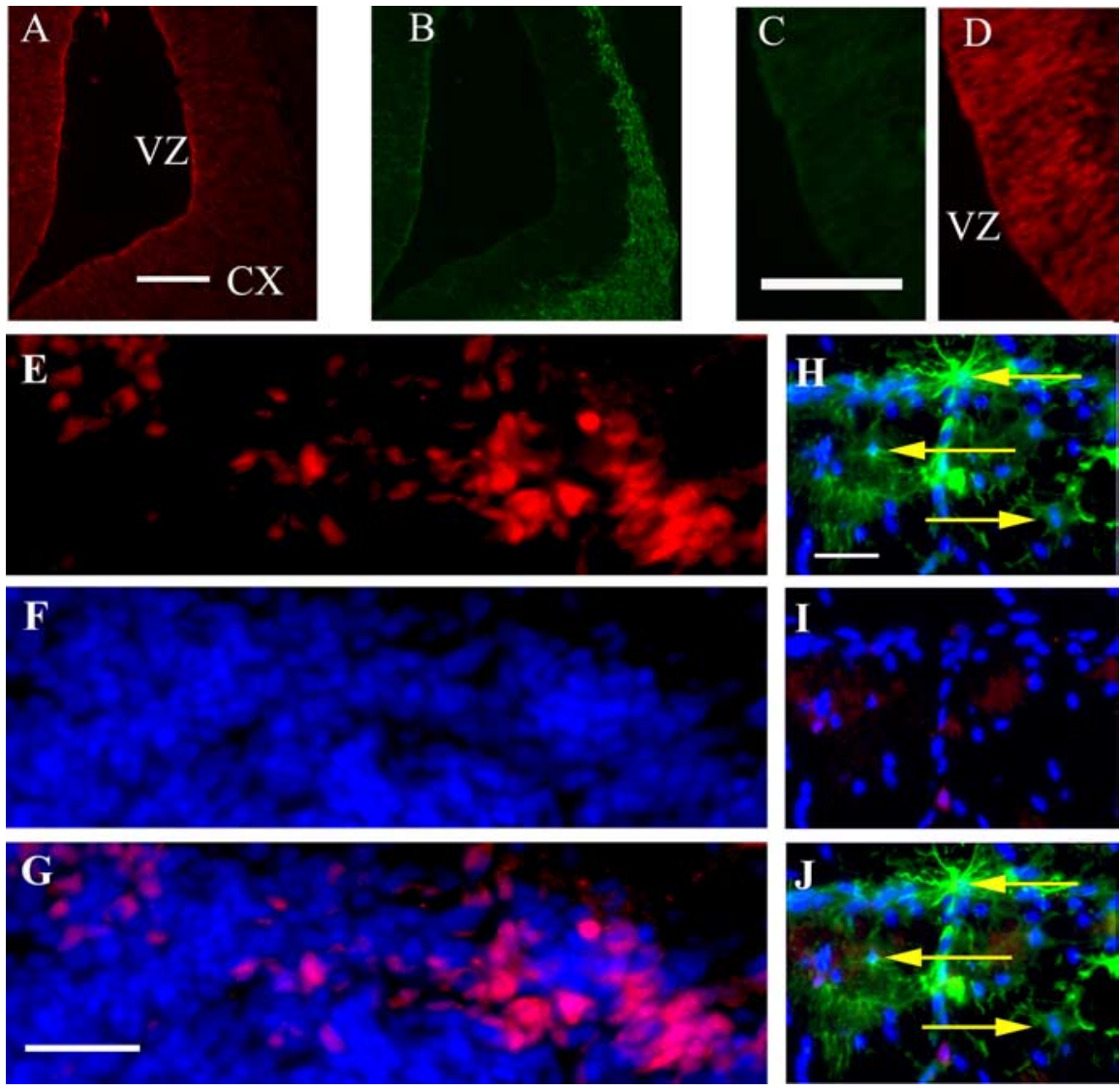

Figure 1. ATF5 is expressed by VZ and SVZ progenitor cells but not in nuclei of mature astrocytes. $A, B, A T F 5$ is highly expressed in the VZ but not in neurons of developing cortex (CX) of E14 rat brain. Coronal sections of E14 rat telencephalon in area of lateral ventricle (dark area in center) were stained for ATF5 ( $\boldsymbol{A}$; red) and tubulin $\beta$ (III) (B; green). C, D, ATF5-positive cells ( $\boldsymbol{D}$; red) in the VZ of E15 telencephalon do not express GFAP (C; green). Coronal section, lateral ventricle is dark area at left. $\boldsymbol{E}-\mathbf{G}, \mathrm{ATF} 5$ is expressed in the postnatal SVZ. Saggital sections of rat P9 brains were stained with anti-ATF5 (E; red) or with $4^{\prime}, 6^{\prime}$-diamidino-2phenylindole (DAPI) to reveal nuclei ( $\boldsymbol{F}$; blue). $\boldsymbol{G}$, Merged images. Note the nuclear localization of ATF5 in clusters of cells in SVZ. $\boldsymbol{H}-\boldsymbol{J}$, ATF5 is either undetectable or in cytoplasm of cortical astrocytes in postnatal brain. Cortical sections of P9 rat brain were stained with either anti-GFAP (green), anti-ATF5 (red), or anti-DAPI (blue). J shows merged image. Note absence of ATF5 staining in nuclei of GFAP + cells with morphology of mature astrocytes. The top arrow shows GFAP + cell with no nuclear and apparent small amount of cytoplasmic ATF5. The middle arrow shows GFAP + cell with cytoplasmic ATF5 staining. The bottom arrow shows GFAP+ cell without apparent ATF5 staining. Scale bars: (in $\boldsymbol{A}, \boldsymbol{C}) \boldsymbol{A}-\boldsymbol{D}, 100 \mu \mathrm{m}$; (in $\mathbf{G}$ ) $\boldsymbol{E}-\mathbf{G}, 50 \mu \mathrm{m}$; (in $\boldsymbol{H}) \boldsymbol{H}-\boldsymbol{J}, 25 \mu \mathrm{m}$.

$11 \mathrm{~d}$ later. Retroviral infection of total and PSA-NCAM SVZ cells was performed by centrifuging the transfected GP2 293 cells, resuspending in serum-free medium, and plating in a cell culture $0.4 \mu \mathrm{m}$ filter insert (Falcon) placed above the SVZ cycling progenitor cell monolayer. The constant exposure to retrovirus achieved in this manner results in infection of nearly $100 \%$ of dividing progenitors. After $5 \mathrm{~d}$, the filters were removed, and the SVZ cells were fixed. For in vivo studies, retrovirus was injected under stereotactic control into the SVZ of postnatal day 1 (P1) rats as described previously (Levison et al., 1993; Zerlin et al., 1995; Kakita and Goldman, 1999). After 7 d, the animals were killed and fixed by transcardial perfusion with $4 \%$ paraformaldehyde.

Immunohistochemistry. Dissociated telencephalic cultures and SVZ cells were fixed and stained as described previously (Angelastro et al., 2003), except that $20 \%$ normal goat serum and no Triton X-100 was used for blocking cultures of SVZ cells. Cultures were immunolabeled as follows: (1) rabbit anti-GFP (1:1000) and mouse anti-nestin (1:200); (2) rabbit anti-GFAP (1:1000), mouse TUJ1 (1:2000), and mouse anti-GFP $\mathrm{IgG}_{1} ;(3)$ mouse anti-GFP $\operatorname{IgG}_{2 \mathrm{a}}(1: 100)$, mouse anti-nestin $(1: 200)$, and rabbit anti-Ki67 (1:1000); (4) mouse anti-GFP $\operatorname{IgG}_{2 \mathrm{a}}$ (1:100), mouse anti-GFAP $\operatorname{IgG}_{1}$, and rabbit anti-ATF5 antiserum (1:500) (Angelastro et al., 2003); or (5) mouse anti-GFP $\operatorname{IgG}_{2 \mathrm{a}}(1: 100)$, mouse $\operatorname{IgG}_{1}$ anti- $\beta$ catenin (1:200), and rabbit anti-GFAP. Overnight incubation was followed by secondary labeling with goat FITC- or Alexa 488-conjugated

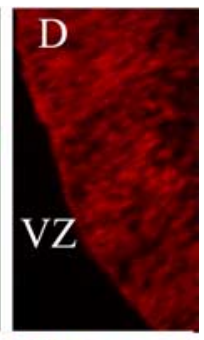

anti-rabbit or anti-mouse antibodies (1:4000), goat tetramethylrhodamine isothiocyanate (TRITC)- or Alexa 568-conjugated anti-rabbit or anti-mouse antibodies, or 7-amino-4methylcoumarin-3-acetic acid (AMCA)conjugated anti-rabbit (1:100) or AMCAavidin $\mathrm{D}$ bound to goat anti-mouse biotinylated $\operatorname{IgG}_{2 \mathrm{a}}$ at $1: 100$.

Brains from P7-P8 animals (perfused as above) were drop-fixed in $4 \%$ paraformaldehyde in PBS buffer for $1 \mathrm{~h}$, cryoprotected in $30 \%$ sucrose overnight, frozen in OCT compound (Tissue-Tek, Miles, Elkhart, IN), and then cryosectioned $(14 \mu \mathrm{m})$. Sections were blocked for $1 \mathrm{~h}$ in $20 \%$ nonimmune goat serum and then incubated in $20 \%$ nonimmune goat serum overnight at $4^{\circ} \mathrm{C}$ with: (1) ATF5 antiserum (1:500) and mouse anti-GFAP $\operatorname{IgG}_{1}$ antibody (1:200); (2) rabbit anti-GFP (1:500) and mouse anti-nestin (1:200); (3) rabbit anti-GFP (1:500) and mouse anti-GFAP (1:200); (4) rabbit anti-GFP (1:500) and mouse anti-tubulin $\beta$ (III) (1:500); or (5) rabbit anti-GFP (1:500) and mouse anti- $\beta$-catenin $(1: 200)$. The sections were incubated subsequently for $1 \mathrm{~h}$ with goat FITC-conjugated anti-rabbit and rhodamineTRITC-conjugated anti-mouse antibodies in $20 \%$ nonimmune goat serum.

For BrdU incorporation and immunostaining, cells were labeled with $10 \mu \mathrm{M}$ BrdU for $5 \mathrm{~h}$ as described previously (Mason and Goldman, 2002) and subsequently fixed and blocked as described for the SVZ above. Incorporated BrdU was labeled with mouse $\operatorname{IgG}_{1}$ anti-BrdU with nuclease as described by the manufacturer (Amersham Biosciences, Arlington Heights, IL). The cells were visualized with rabbit antiGFP, goat anti-rabbit FITC, and goat antimouse TRITC-conjugated antibodies.

Confocal microscopy. Cultures of adherent neurospheres were immunostained and examined by confocal microscopy as described previously (Angelastro et al., 2003). Confocal microscopy was performed on a Bio-Rad (Hercules, CA) confocal microscope system 1024ES (neurosphere cultures). Images were obtained under conditions that were identical for both fluorochromes.

Statistical analyses. Comparisons for pairs of data were conducted with Student's $t$ test.

\section{Results}

\section{ATF5 is downregulated during forebrain} astrocyte development

Our previous findings using an ATF5-specific antiserum indicate that during rat embryonic development, ATF5 is highly expressed in the GFAP-negative neural epithelium of the VZ but is little or not at all expressed in postmitotic cortical neurons (Angelastro et al., 2003) (Fig. 1A-D). Examination of postnatal forebrain (P9) revealed that ATF5 continues to be expressed in the $\mathrm{VZ}$ (data not shown) as well as within a subpopulation of cells in the SVZ (Fig. $1 E-G$ ). The expression of ATF5 in the SVZ was primarily nuclear, and the positive cells tended to be clustered. To examine ATF5 expression in cortical astrocytes, sections from P9 forebrain were costained with anti-GFAP and anti-ATF5 (Fig. $1 H-J)$. GFAP + cells with the morphology of astrocytes (compare arrows) did not show nuclear expression of ATF5. In some cases (compare bottom arrow), the cells did not detectably ex- 
press ATF5, whereas in others (compare middle arrow), they appeared to have a low level of cytoplasmic ATF staining. These observations indicate that $\mathrm{VZ}$ and postnatal SVZ progenitor cells express nuclear ATF5, whereas mature cortical astrocytes do not. When present in cortical astrocytes, ATF5 appears to be cytoplasmic and hence is unlikely to act as a transcription factor.

As another approach to the question of ATF5 expression in astrocytes and in progenitor cells that become astrocytes, we grew clonal neurosphere cultures from newborn mouse SVZ or hippocampal dentate gyrus in presence of FGF2 and EGF and then permitted them to differentiate into neurons and glia by plating on a polylysine/laminin substrate in presence of serum (Kukekov et al., 1997, 1999; Laywell et al., 1999, 2000, 2002). Essentially all of the undifferentiated cells at the centers of the cultures were strongly positive for ATF5 expression but negative for GFAP (Fig. $2 A$ ). In contrast, cells that had migrated from the center and acquired a flatter, processbearing appearance were negative for ATF5 expression and strongly positive for GFAP (Fig. 2C). Finally, we found that cells located between the centers of the cultures and the peripheral astrocytes showed the presence of low but detectable levels of both nuclear ATF5 and of filamentous GFAP (Fig. 2B). These findings support the idea that ATF5 is present in progenitor cells in neurospheres and that ATF5 is downregulated in such cells as they undergo the transition into mature astrocytes.

\section{Constitutive expression of ATF5 represses, but dominant- negative ATF5 and ATF5 siRNA leads to, astrocytic differentiation of cultured embryonic telencephalic neural progenitors}

The presence of ATF5 in embryonic neural progenitors and its loss from nuclei and downregulation as they develop into astrocytes led us to assess whether ATF5 expression functionally influences this differentiation. We first established cultures from dissociated E14 and E15 rat telencephali, which initially consist mainly of neural progenitors and preexisting neurons and contain low numbers of astrocytes. When the cultures are maintained with $5 \%$ fetal bovine serum, formation of astrocytes from neural progenitors is induced, and significant numbers of astroglia are present after postplating day 11 (Qian et al., 2000; Barnabe-Heider and Miller, 2003). To test the effects of constitutive ATF5 expression and of interference with ATF5 activity, the cultures were infected at $1 \mathrm{~d}$ in vitro with retrovirus constructs expressing eGFP, eGFP-FLAG-NTAzip-ATF5, or FLAG-ATF5 and $e G F P$ (Angelastro et al., 2003), and $10 \mathrm{~d}$ later, the infected cells were examined for morphology and expression of markers. Azip-ATF5 lacks the ATF5 DNA-binding and activation domains, has enhanced capacity to interact with and neutralize binding partners, and has been shown to act effectively as a dominant negative that interferes with functional actions of ATF5 (Angelastro et al., 2003). Neural progenitors infected with the control virus (eGFP alone) either exhibited a round, undifferentiated shape (Fig. 3Aa) or acquired a process-bearing morphology (Fig. $3 A b$ ). Immunostaining revealed that all of the processbearing cells expressed GFAP and comprised $20-25 \%$ of the total $\mathrm{GFP}+$ cells (Fig. $3 A b, B, C$ ). In contrast, neural progenitors infected with the ATF5 retrovirus did not show a glial morphology or expression of tubulin $\beta$ (III) and formed spherical colonies (Fig. 3Ac, $A d$ ), and many fewer expressed GFAP (Fig. $3 A c, A d, B, C)$. Finally, a loss of ATF5 function achieved with the Azip-ATF5 retrovirus more than doubled (compared with controls) the proportion of infected cells that were GFAP+ (Fig. $3 A e, A f, B, C)$, and all of these showed a process-bearing morphology (Fig. 3Ae,Af). This increase in astrocytes did not appear to result from a preferential proliferation of astrocytes, because Azip-ATF5 expression severely inhibits proliferation (see below). Thus, ATF5 appears to block and Azip-ATF5 to lead to astroglial differentiation of cultured embryonic neural progenitor cells.

To corroborate our results with Azip-ATF5 and to verify that the effects achieved with this protein are caused by interference with ATF5 function rather than to irrelevant interactions with other transcription factors, we used an siRNA that selectively downregulates ATF5 (Angelastro et al., 2003). This construct reduced the proportion of cells expressing endogenous ATF5 by nearly two-thirds and, like expression of Azip-ATF5, doubled the proportion of GFAP+ cells (Fig. 3D). As with Azip-ATF5, most of the latter possessed a process-bearing astrocytic morphology. Transfection with an irrelevant siRNA (targeting rat plenty of $\mathrm{SH}_{3} \mathrm{~s}$ ) had no effect (data not shown).

\section{Reciprocal interactions between ATF5 and CNTF}

In the above experiments, astroglial differentiation either occurred spontaneously or was driven by factors present in the cultures. We next assessed the effect of ATF5 on the actions of CNTF, a defined factor that promotes differentiation of neural progenitor cells into astrocytes (Park et al., 1999; Qian et al., 2000; Menard et al., 2002). We again used serum-containing medium, because this provided a population of neural progenitors as well as a moderate level of basal astrocyte formation that had the potential to be manipulated by our experimental treatments. For cells infected with the control retrovirus, CNTF nearly doubled (from $\sim 20$ to $\sim 40 \%$ ) the proportion of progenitors that became GFAP + (Fig. 3B,C). CNTF could not, however, override the suppression of astrocyte development produced by constitutive ATF5 expression (Fig. 3 B, C). The suppression of astrocyte development was not caused by or accompanied by a diversion of neural progenitor differentiation toward a neuronal phenotype, because ATF5 also suppressed the formation of TUJ1-positive cells, also in the presence or absence of CNTF (Fig. 3C).

As noted above, the loss of ATF5 function, produced by the Azip-ATF5 retrovirus, doubled the proportion of cells that were GFAP +. Adding CNTF to the medium of Azip-ATF5-infected cells did not further increase the proportion of GFAP + cells, 
A
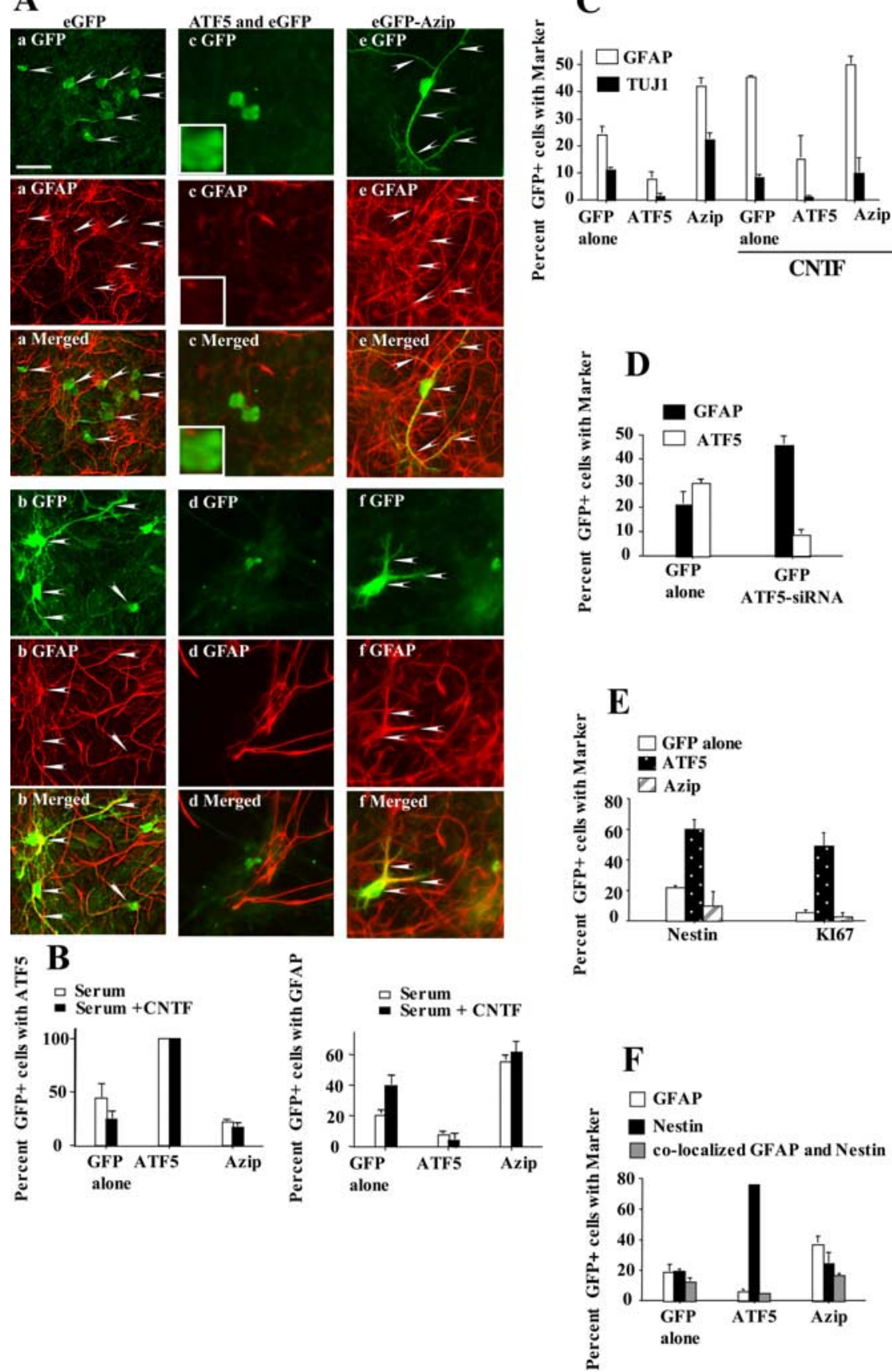

Figure 3. ATF5 represses and Azip-ATF5 and ATF5 siRNA accelerate astrocyte differentiation in cultures of E15 telencephalic neural progenitor cells. A, Effects of ATF5 and Azip-ATF5 on morphology and GFAP expression of cultured E15 telencephalic cells. After $1 \mathrm{~d}$ in culture, cells were infected with retroviruses expressing eGFP, FLAG-ATF5 and eGFP, or eGFP-Azip-ATF5. On the 10th day after infection, the cultures were immunostained for expression of eGFP, GFAP, nestin, and ATF5. The panel shows examples of cells costained for eGFP and GFAP expression under each indicated condition. The inset in c shows a magnified version of bottom cell cluster. $\boldsymbol{B}$, CNTF downregulates ATF5 expression, and ATF5 represses CNTF-promoted genesis of astrocytes. Experimental conditions were as in $\boldsymbol{A}$ except that CNTF was added to the medium as indicated. Values represent means \pm SEM for three cultures in which at least 200 infected cells were evaluated per culture for expression of ATF5 (left) or GFAP (right). Student's t test analysis of infected cells for ATF5 expression (left) without versus with CNTF: eGFP alone, $p<0.03$; GFAP expression (right) without versus with CNTF: eGFP alone, $p<0.02$. There were no other significant differences. Comparable results were achieved in three independent experiments. C, ATF5 represses and Azip-ATF5 (Azip) promotes astroglial differentiation in both the absence and presence of CNTF. Experimental conditions were as in $A$ except that CNTF was added to the medium as indicated. Values represent the mean \pm SEM for three cultures in which at least 300 transfected cells were evaluated per culture. Student's $t$ test analysis of infected cells: GFAP expression without versus with CNTF: eGFP alone, $p<0.005$; ATF5 retrovirus, no significant difference; Azip retrovirus, $p<0.04$; TUJ1 expression without versus with CNTF: eGFP alone, $p<0.04$; ATF5 retrovirus, no significance; Azip retrovirus, $p<0.04$. Left panel (no CNTF) for GFAP expression: eGFP alone versus ATF5 retrovirus, $p<0.003$; eGFP alone versus Azip retrovirus, $p<0.003$. Left panel (no CNTF) for TUJ1 expression: eGFP alone versus ATF5 retrovirus, $p<0.001$; eGFP alone versus Azip retrovirus, $p<0.005$. Right panel (plus CNTF) for GFAP expression: eGFP alone versus ATF5 retrovirus, $p<0.006$; eGFP showing that the effects of the two treatments are not additive. In fact, the proportion of GFAP + cells in control cultures treated with CNTF (40\%) was similar to that for cells expressing Azip-ATF5 in the absence or presence of CNTF (Fig. $3 B, C$ ). Thus, downregulation of ATF5 and exposure to CNTF drive astrocyte differentiation to the same extent. The lack of additivity suggested that CNTF might act by decreasing ATF5 levels. In agreement with this, in control cultures, CNTF treatment decreased by approximately one-half the proportion of cells expressing endogenous ATF5 (Fig. 3B). This decrease (a difference of $\sim 20 \%$ of the total cell number) was similar to the increase in the proportion of GFAP + cells promoted by CNTF and is thus consistent with the interpretation that induction of astrocyte differentiation by CNTF results in and requires the downregulation of ATF5. CNTF did not reduce expression of exogenous (retroviralexpressed) ATF5 (Fig. 3B), indicating that

alone versus Azip retrovirus $p<0.06$. Right panel (plus CNTF) for TUJ1 expression: eGFP alone versus ATF5 retrovirus, $p<0.002$; eGFP alone versus Azip retrovirus, not significant. Comparable results were achieved in three independent experiments. D, Downregulation of ATF5 expression by ATF5 siRNA promotes astrocyte differentiation. Cultured E15 telencephalic cells were transiently transfected with pCMS-eGFP with or without ATF5 siRNA. Seven days after transfection, GFP + cells were immunostained for expression of ATF5 or GFAP as indicated. Values represent the mean \pm SEM for six cultures in which at least 200 transfected cells were evaluated per culture. Comparable results were achieved in 10 independent experiments. Student's $t$ test analysis of transfected cells: GFAP expression for eGFP alone versus GFP plus ATF5 siRNA, $p<0.03$; ATF5 expression for eGFP alone versus eGFP plus ATF5 siRNA, $p<0.007$. E, ATF5 increases the number of nestin + cells and of dividing cells in cultures of E15 telencephalic neural progenitors. Experimental conditions were as in $\boldsymbol{A}$ with infected cells evaluated for expression of nestin or Ki67 antigen. Values represent the mean \pm SEM for three cultures in which at least 200 transfected cells were evaluated per culture. Comparable results were achieved in three independent experiments. Student's $t$ test analysis of infected cells, nestin expression: eGFP alone versus ATF5 retrovirus, $p<0.001$; eGFP versus Azip retrovirus, $p<0.01$; Ki67 expression: eGFP versus ATF5, $p=0.002$; eGFP versus Azip, not significant. $\boldsymbol{F}$, The nestin + cells generated in cultures of E15 telencephalic neural progenitors by ATF5 do not coexpress GFAP. Experimental conditions were as in $\boldsymbol{A}$ with infected cells evaluated for expression of GFAP and/or nestin. Values represent the mean \pm SEM for three cultures in which at least 200 transfected cells were evaluated per culture. Student's $t$ test analysis of infected cells, GFAP expression: eGFP alone versus ATF5 retrovirus, $p<0.02$; eGFP alone versus Azip retrovirus, $p<0.02$; nestin expression: eGFP alone versus ATF5 retrovirus, $p<0.0001$; eGFP alone versus Azip retrovirus, not significant; colocalized GFAP and nestin: eGFP versus ATF5 retrovirus, $p<0.005$; eGFP versus Azip retrovirus, not significant. 
regulation of ATF5 by CNTF is at the transcriptional rather than posttranslation level.

\section{Overexpression of ATF5 induces progenitor cells to remain in the cell cycle and to continue expression of nestin}

If ATF5 blocks embryonic telencephalic cells from differentiating into astrocyte or neurons, then does it maintain them as proliferating progenitors? To determine this, we infected E15 telencephalic cultures with control, ATF5, and Azip-ATF5 retroviruses and 11-24 d later immunostained them for expression of Ki67, a marker for cells in cycle. ATF5 expression increased the proportion of Ki67+ cells by $\sim 10$ fold, to $50 \%$ of the population (Fig. $3 E$ ). We also assessed the expression of nestin, which is present in proliferating embryonic VZ neural progenitors (Eliasson et al., 1999; Wei et al., 2002; Filippov et al., 2003) but also in some astrocytes, especially those in a reactive state (Schmidt-Kastner and Humpel, 2002; Wei et al., 2002). Constitutive ATF5 expression increased the proportion of nestin + cells in the cultures by more than threefold (to 60-80\%) (Angelastro et al., 2003), but very few of these coexpressed GFAP (Fig. $3 E, F$ ). This contrasts with control cells and those expressing Azip-ATF5, in which approximately two-thirds of the nestin + cells coexpress GFAP (Fig. $3 F$ ). Thus, constitutive ATF5 expression maintains cultured embryonic neural progenitor cells in a proliferative state characterized by expression of nestin and by the absence of neuronal and astroglial markers.

\section{ATF5 represses, and Azip-ATF5 leads to, astrocytic} differentiation of cultured postnatal PSA-NCAM+ SVZ cells Because many astrocytes of the forebrain originate postnatally from progenitors in the SVZ (Marshall et al., 2003), for review we examined the effects of expressing ATF5 or Azip-ATF5 in SVZ cells, first in culture and then in vivo. For culture studies, we dissected the SVZ from the P1 rat forebrain, dissociated the cells, and immunopanned with an anti-PSA-NCAM antibody. This antigen is expressed on the migratory SVZ cells that give rise to oligodendrocytes, astrocytes, and olfactory interneurons and distinguishes this population from VZ cells, which do not express PSA-NCAM (Marshall and Goldman, 2002). The freshly isolated cells were continuously exposed for $5 \mathrm{~d}$ to retroviruses expressing eGFP (control), eGFP-Flag-Azip-ATF5, or Flag-ATF5 and eGFP via a transmembrane apparatus (see Materials and Methods) to achieve a high rate of infection. On the fifth day, cells were exposed to BrdU for $5 \mathrm{~h}$ and then fixed and stained for expression of eGFP, GFAP, nestin, tubulin $\beta$ (III), and BrdU.

More than $80 \%$ of the cells infected with the control eGFP virus exhibited a round morphology (Fig. $4 A a$ ), and an average of $10 \%$ (range, 3-20\% in three experiments) expressed GFAP with a similar proportion expressing nestin (Fig. 4D). A small proportion of such cells $(2 \%)$ exhibited a neuronal marker [tubulin $\beta$ (III)] (Fig. $4 B$ ), whereas 5\% were positive for BrdU incorpora-
B

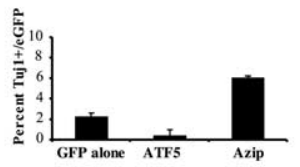

D

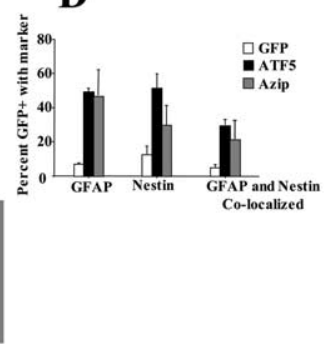

C

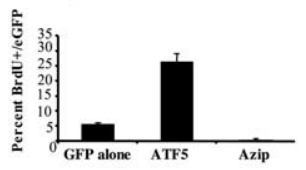

E

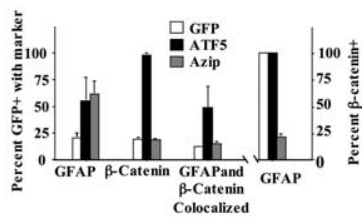

Insert

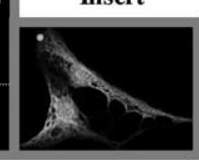

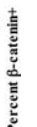

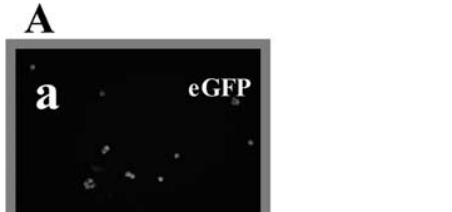


presence did not give us a clear indication of phenotype. Therefore, we examined expression of $\beta$-catenin, a protein that is expressed in the VZ, where it appears to play a role in promoting VZ cell proliferation (Chenn and Walsh, 2002, 2003). We found that all cells constitutively expressing ATF5 were $\beta$-catenin + (Fig. $4 E$ ). This contrasts with the $\sim 20 \%$ of control or Azip-ATF5infected cells that expressed $\beta$-catenin. Moreover, double labeling for GFAP and $\beta$-catenin expression revealed that in ATF5infected cultures, all cells that were GFAP+ were also $\beta$-catenin + . In contrast, less than one-quarter of the cells infected with the Azip-ATF5 retrovirus coexpressed the two markers (Fig. 4E). These observations support a model in which the constitutive expression of ATF5 suppresses differentiation, maintains the cells in a proliferative state, and induces expression of markers characteristic of VZ cells. In contrast, interference with ATF5 function leads to the differentiation of PSA-NCAM+ SVZ progenitors into neurons and glia.

In vivo expression of exogenous ATF5 in SVZ cells represses astrogenesis and promotes a VZ-like phenotype, whereas Azip-ATF5 leads to astrogenesis

To determine whether our in vitro observations apply to progenitors in vivo, we next used stereotactic injection to infect proliferating SVZ cells in the P1 rat forebrain with the various retroviruses. With this protocol, retroviruses infect the unipolar or bipolar cells that migrate from the SVZ either radially to form glia or through the rostral migratory stream to form interneurons (Suzuki and Goldman, 2003). VZ cells are not infected. The animals were killed $7 \mathrm{~d}$ later, and the fates of infected cells were monitored by immunostaining for eGFP and various markers. Cells infected with the control virus were distributed among the SVZ, corpus callosum, cortex, and olfactory bulb; none were detected in the VZ (supplemental Fig. 1, available at www.jneurosci.org as supplemental material, Fig. $5 A$ ). As established previously (Suzuki and Goldman, 2003), those that migrated radially into white matter, cortex, and striatum developed into astrocytes and oligodendrocytes, whereas those that migrated through the rostral migratory stream into the olfactory bulb developed into interneurons (Figs. 6, 7 and data not shown). When we injected the ATF5 retrovirus, in contrast, we found that nearly $70 \%$ of cells resided in the $\mathrm{VZ}$, and the remaining population was within the SVZ; none of the labeled cells were detected outside these germinal layers (supplemental Fig. 1, available at www.jneurosci.org as supplemental material, Figs. 5A, 6, 7). Labeled cells appeared round to polygonal in morphology, some displaying a single cytoplasmic process oriented radially (Figs. 6, 7). Thus, a majority of the cells constitutively expressing ATF5 displayed both the anatomic localization and morphology of VZ cells.

To characterize the infected cells further, we immunostained them for GFAP, nestin, and $\beta$-catenin. Cells constitutively expressing ATF5 showed a strikingly different pattern from control cells (Figs. 5B, 6A-H, 7A-P). Although essentially all of the former expressed $\beta$-catenin, none of the latter were positive for this protein (Figs. 5B, 6A-H). Furthermore, nearly all ATF5 cells were nestin + , whereas $<5 \%$ of the control population expressed nestin (Figs. $5 B, 7 A-D, I-L$ ). Finally, $>80 \%$ of the ATF5 retrovirus-infected cells expressed GFAP, whereas $<30 \%$ of the control population was GFAP+ (Figs. $5 B, 7 E-H, M-P$ ). These differences between ATF5-infected cells and control virusinfected cells are similar to those observed in postnatal SVZ cells in vitro (see above and Fig. 4) and, coupled with the morphology and position of the cells, indicates that constitutive expression of ATF5 maintains/promotes their status as neural progenitors.

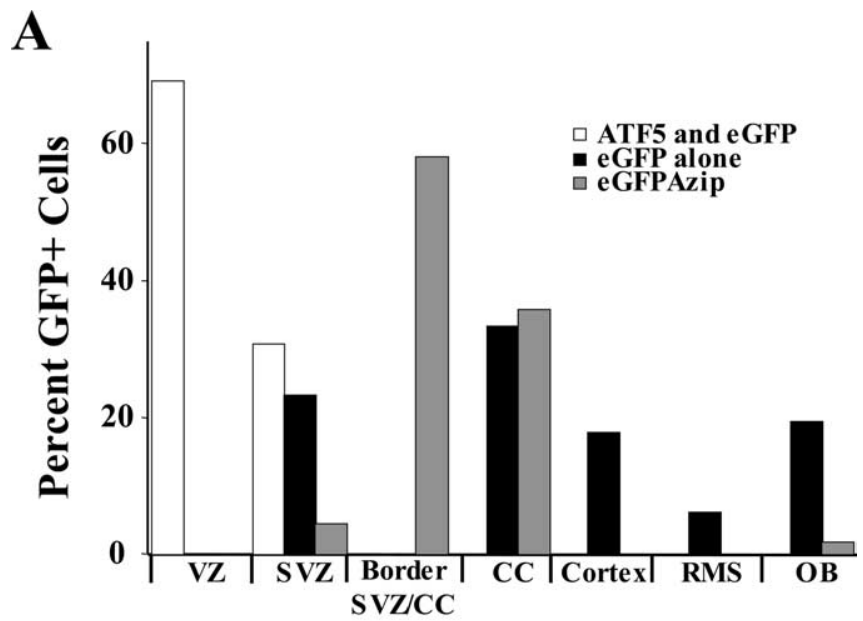

Location

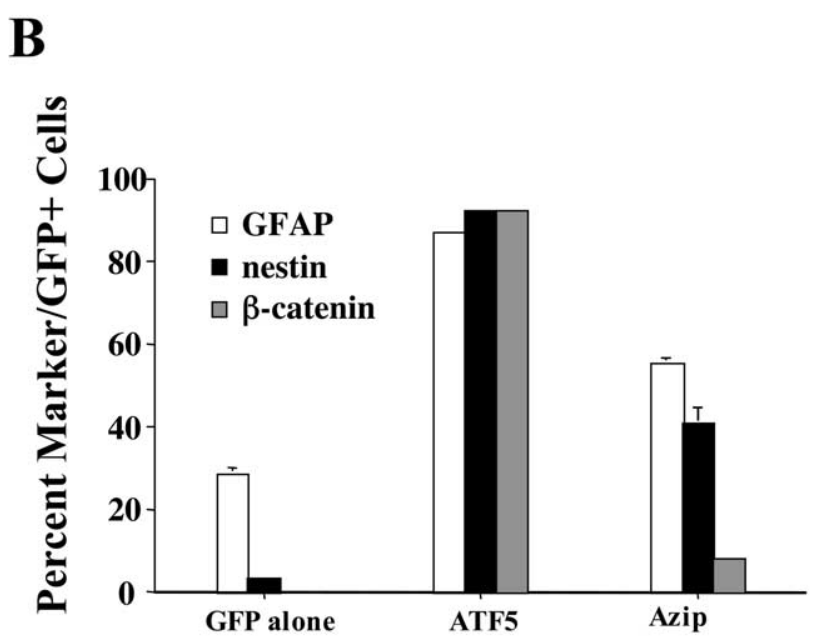

Infection

Figure 5. Constitutive expression of ATF5 and Azip-ATF5 affects fate of SVZ neural progenitor cells in vivo. SVZ neural progenitor cells in vivo. A, Quantification of the effects of ATF5 and Azip-ATF5 on the migratory behavior of SVZ neural progenitor cells. The SVZ of P1 rats was stereotactically injected with retrovirus expressing eGFP (control), eGFP plus ATF5, or eGFPAzip-ATF5. One week later, the animals were killed, and brain sections were immunostained for GFP to reveal the locations of infected cells. The numbers of infected neurons assessed per brain ranged from 112 to 156 . Comparable results were found in two additional brains. $\mathrm{CC}$, Corpus callosum; RMS, rostral migratory stream; $\mathrm{OB}$, olfactory bulb. $\boldsymbol{B}, \mathrm{ATF} 5$ and Azip-ATF5 affect the expression of markers by SVZ neural progenitor cells in vivo. Experimental conditions are as in $\boldsymbol{A}$. Data represent mean \pm SEM for data from three brains; at least 140 cells were assessed per brain.

To determine whether the effects achieved by short-term constitutive expression of ATF5 are sustained, we also examined animals 3.5 months after injection of SVZ cells with the ATF5 and control retroviruses. This revealed that the ATF5-infected cells had remained at the surface of the ventricle and had proliferated to form a multilayered, hyperplastic mass (Fig. 6N). All labeled cells in these brains were associated with these masses; none had migrated into the overlying corpus callosum. The cells in these masses stained positively for $\beta$-catenin, and most were positive for nestin and GFAP (data not shown), further supporting the idea that they represent a hyperplastic VZ. 


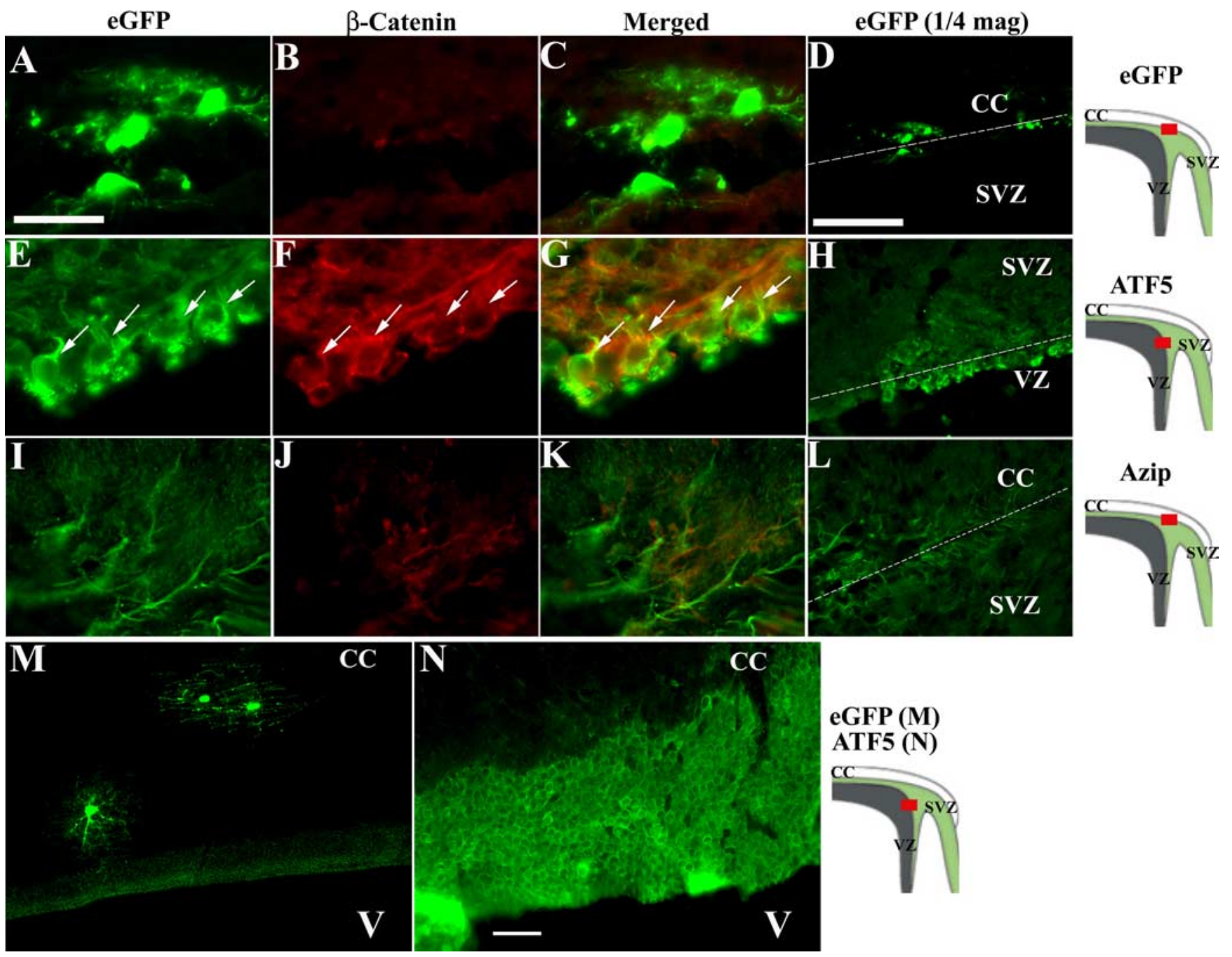

Figure 6. Constitutive expression of ATF5 and Azip-ATF5 in SVZ neural progenitor cells affects their morphology, localization, proliferation, and expression of $\beta$-catenin. Experimental conditions are as in Figure 5 except for $\boldsymbol{M}$ and $\boldsymbol{N}$, in which animals were killed and brains examined 3.5 months after injection with retrovirus expressing eGFP alone ( $\boldsymbol{M}$; showing mature glial cells in the white matter) or eGFP and Flag-tagged ATF5 ( $\boldsymbol{N}$; showing a hyperplastic mass at the ventricular surface). The diagrams to the right of each row depict the treatment and brain areas at which the photographs were taken. Cells were stained as indicated for expression of GFP (green) and $\beta$-catenin (red). The arrows in $\boldsymbol{E}$ - $\boldsymbol{G}$ show positions of the same cells, each with the characteristic morphology of VZ neural progenitors. Scale bars: $A, 25 \mu \mathrm{m} ; \boldsymbol{D}, 100 \mu \mathrm{m}$; (in $\boldsymbol{N}) \boldsymbol{M}, \boldsymbol{N}, 40 \mu \mathrm{m}$. CC, Corpus callosum; $V$, ventricle.

Expression of d/n Azip-ATF5 also altered the phenotype and distribution of infected cells, but in a very different manner. The majority of labeled cells were restricted to the border between the SVZ and the overlying white matter or the white matter itself (supplemental Fig. 1, available at www.jneurosci.org as supplemental material, Figs. 5A, 6). These had the appearance of process-bearing glia (Figs. $6 I-L, 7 Q-X)$ ). A small number reached the olfactory bulb, where they acquired the morphology of interneurons (Fig. 5A and data not shown). Thus, cells emigrated from the SVZ, but as a whole, the population did not migrate normally, taking up residence as if they stopped migration too early. Cells infected with d/n Azip-ATF5 also showed a pattern of marker expression that differed from that of control and ATF5-infected cells. Compared with controls, there was a doubling (from 25 to 50\%) in the proportion of cells expressing GFAP, and $>40 \%$ were nestin + (Figs. $5 B$, $7 Q-X$ ). Very few, however, expressed $\beta$-catenin (Figs. $5 B, 6$ ). Thus, the premature loss of ATF5 function leads to glial differentiation in the white matter.

\section{Discussion}

ATF5 negatively regulates neural progenitor differentiation into multiple lineages

The transcription factor ATF5 is expressed by VZ cells of the embryonic and early postnatal forebrain but is downregulated, and the lost from nuclei as progenitors differentiate into neurons (Angelastro et al., 2003) and astrocytes (present data). Thus, marked changes in ATF5 expression accompany the neuronal and glial differentiation of neural progenitors. Furthermore, functional experiments show that ATF5 appears to be a negative regulator of neuronal and glial differentiation.

In this study, we observed that ATF5 blocks the differentiation of neural progenitors into astrocytes. Constitutive expression of ATF5 inhibited the development of astrocytes both in vitro and in vivo, whereas the loss of ATF5 expression (with siRNA) or function (with $\mathrm{d} / \mathrm{n}$ Azip-ATF5) enhanced astrocyte differentiation. Constitutively expressed ATF5 inhibited astrocyte differentiation in the presence of CNTF, a factor that promotes astrocyte development. We also noted that CNTF appeared to decrease ATF5 
eGFP

GFP/Nestin
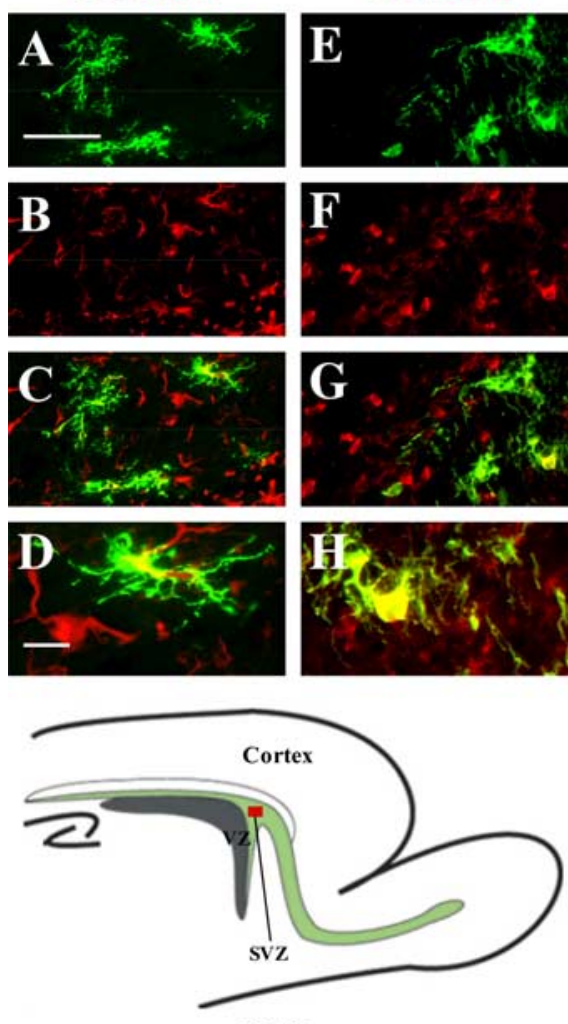

eGFP
GFP/GFAP
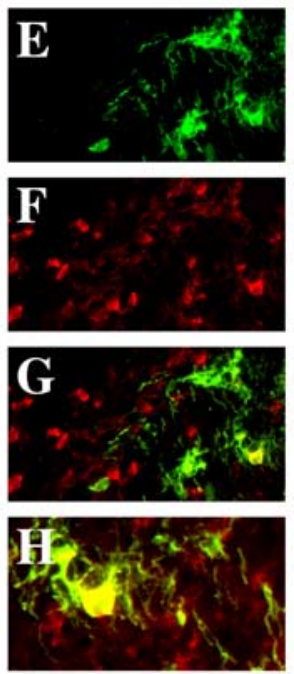

GFP/Nestin
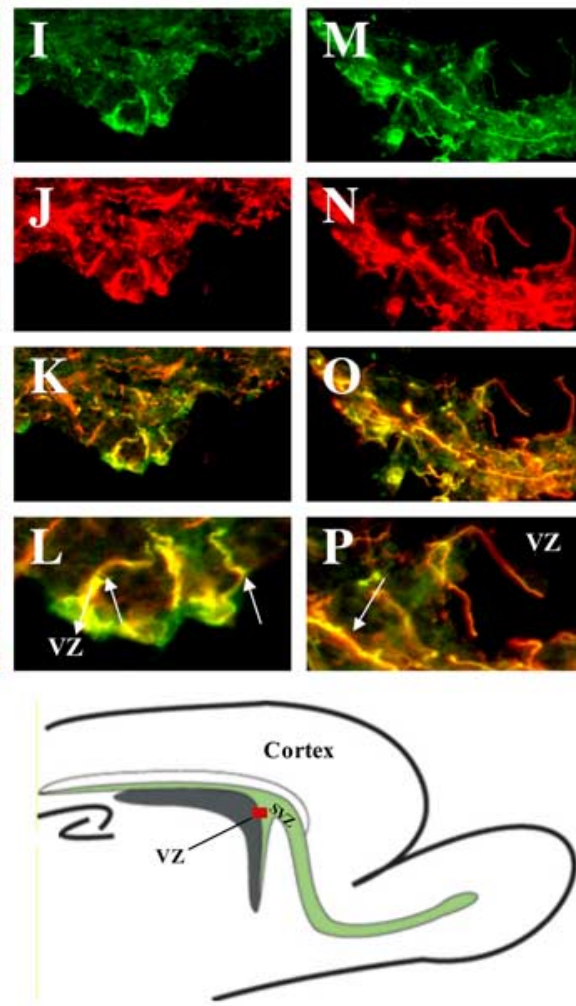

ATF5

GFP/GFAP
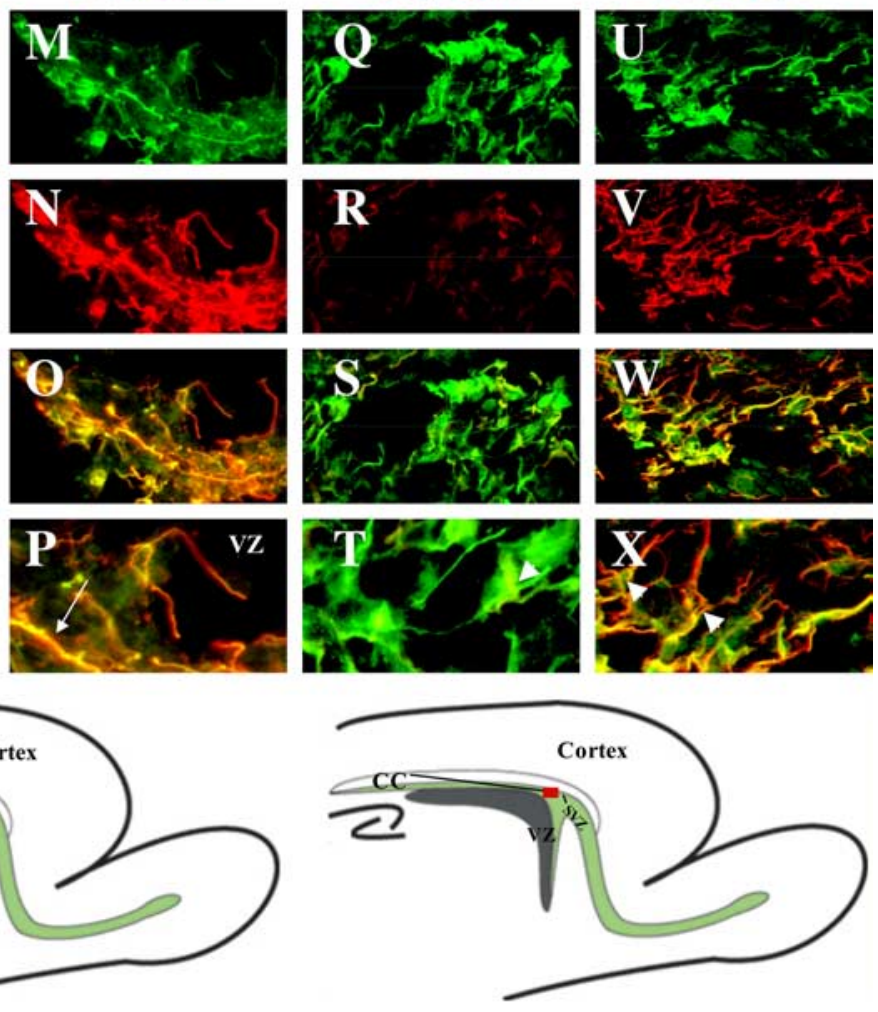

Azip

Figure 7. Constitutive expression of ATF5 and Azip-ATF5 in SVZ neural progenitor cells affects their morphology, localization, and expression of nestin and GFAP. Experimental conditions are as in Figure 5. Diagrams below each row depict the treatment and brain areas at which the photographs were taken. Cells were stained as indicated for expression of GFP, nestin, or GFAP. The third horizontal row shows merged images; the fourth horizontal row shows $4 \times$ magnifications to highlight cell morphology. Cells with constitutive ATF5 expression display a simple morphology in which a single long process (arrows) extends from a round cell body. In contrast, cells expressing Azip-ATF5 have a complex morphology in which several long, thick processes extend from irregularly shaped cell bodies (arrowheads). Scale bars: (in $\mathbf{D}) \mathbf{D}, \boldsymbol{H}, \boldsymbol{L}, \boldsymbol{P}, \boldsymbol{T}, \boldsymbol{X}, 10 \mu \mathrm{m}$; (in $\boldsymbol{A}) \boldsymbol{A}-\boldsymbol{C}, \boldsymbol{E}-\mathbf{G}, \mathbf{I}-\boldsymbol{K}, \boldsymbol{M}-\mathbf{O}, \mathbf{Q}-\mathbf{S}, \boldsymbol{U}-\boldsymbol{W}, 25 \mu \mathrm{m}$. CC, Corpus callosum.

expression in progenitors, suggesting that this factor may both promote astrocyte genesis and remove a restraint on differentiation. This function appears parallel to the in vitro effects of NGF and NT3 in promoting neuronal differentiation and also downregulating ATF5 (Angelastro et al., 2003). In additional studies (Mason et al., 2005), we observed that ATF5 is undetectable in nuclei of mature oligodendroglia but is expressed in nuclei of O4+ oligodendrocyte precursors. Moreover, constitutive ATF5 expression maintains such oligodendendrocyte precursors in the proliferative state and blocks their differentiation into mature oligodendroglia; in contrast, d/n ATF5 expression in $\mathrm{O} 4+$ precursors drives their exit from the cycle and oligodendroglial maturation. Thus, ATF5 appears to negatively regulate the differentiation of neural progenitor cells into all three lineages of neural cells. In this role, ATF5 does not play an instructive role in determining the fate of progenitors but rather behaves as a general repressor of their differentiation into either neurons or glia. Stated another way, ATF5 expression appears to be subject to regulation by a variety of extracellular signals that also convey instructive information regarding fate.

Although ATF5 does not appear to play an instructive role in the lineage decision of neural progenitors, it is possible that its downregulation permits other transcription factors to act is this role. For instance, neurogenin is reported to promote neurogenesis but to inhibit genesis of astroglia (Sun et al., 2001). It will be thus of interest to explore the relationship, if any, between expression of ATF5 and that transcription factors that specify neural cell lineage.

ATF5 may be one of a group of transcription factors that negatively regulate neural differentiation. Recent studies have identified SoxB1 family members as transcription factors that, like ATF5, block differentiation of neural progenitors and maintain them in a proliferative state (Bylund et al., 2003; Graham et al., 2003). In particular, such work shows that SoxB1 family members interfere with the differentiation of neural progenitors into neurons; it remains to be seen whether such actions are restricted only to the neuronal lineage or whether, like ATF5, they will also include effects on glial lineages. In either case, it will be of interest to establish the relationship, if any, between the mechanisms of action of SoxB1 and ATF5 proteins.

Can ATF5 reverse the transition between VZ and SVZ cells? An unanticipated result in both our in vivo and in vitro study of SVZ cells is that the constitutive expression of ATF5 not only blocked their differentiation but also changed their properties and, in the in vivo case, their localization, to those characteristic of VZ cells. Thus, unlike SVZ cells infected with control virus, many of the SVZ cells constitutively expressing ATF5 were positive for GFAP, nestin, and $\beta$-catenin and negative for PSANCAM. Furthermore, in vivo, in addition to the changes in mark- 
ers, they acquired the morphology and anatomic localization of VZ cells. Note that their distribution corresponds to that of cells expressing endogenous ATF5 in the embryonic and early postnatal forebrain (Fig. 1). Moreover, when examined 3.5 months after infection, the cells had proliferated to form a multilayered mass extending from the ventricle.

Presumably, SVZ cells arise from local VZ cells or from the ventral VZ, from which many SVZ cells migrate dorsally (Marshall et al., 2003). Nothing is known about the mechanisms by which VZ cells transform into SVZ cells. Our observations suggest that the downregulation of ATF5 plays a role in this process and imply that such a transition is reversible with increased expression of ATF5. However, although SVZ cells may have the potential to revert to VZ cells with overexpression of ATF5, there is presently no evidence that such a transition occurs under normal circumstances. Constitutive expression of ATF5 promotes proliferation, but it does not limit migration, because the progenitors were able to migrate from the SVZ back to the VZ. Recently, Noctor et al. (2004) showed that during normal development, SVZ cells are able to migrate retrograde to the ventricle.

The upregulation of $\beta$-catenin in cells overexpressing ATF5 is of particular interest. $\beta$-Catenin promotes and is required for proper proliferation of neural progenitors (Chenn and Walsh, 2002, 2003). This is consistent with our observation that constitutive ATF5 expression promotes continued proliferation by both VZ and SVZ cells in culture and in vivo. The mechanism by which ATF5 affects $\beta$-catenin expression is currently unclear and merits additional investigation.

\section{ATF5 loss of function accelerates astrocyte differentiation: in vivo consequences for migration}

One outcome of ATF5 loss of function in vivo was that the glial progenitors that would have colonized the white matter, cortex, and striatum did not show the normal pattern of migration but appeared only at the border of the SVZ and white matter. It is possible that a rapid loss of ATF5 function caused a premature differentiation of these progenitors cells into glia, which in turn may have caused a premature cessation of their normal migration. Thus, ATF5 loss of function in the SVZ may force the cells to assume a mature nonmigratory astrocytic phenotype.

We noted previously that although loss of ATF5 function was not sufficient to induce neuronal differentiation of PC12 cells, loss of ATF5 function accelerated the initial rate of NGFpromoted neurogenesis in PC12 cell cultures (Angelastro et al., 2003). Moreover, in embryonic neural progenitor cell cultures, in which there appears to be endogenous synthesis and release of neurotrophic factors, ATF5 loss of function also substantially accelerated neuronal differentiation (Angelastro et al., 2003). The present experiments reveal similar effects in which, as judged by both markers and morphological criteria, ATF5 loss of function accelerates the differentiation of both embryonic and postnatal neural progenitors into astrocytes in culture and accelerates astrocyte differentiation in vivo as cells emigrate from the SVZ. In addition, consistent with its suppression of proliferation and promotion of differentiation, the loss of ATF5 function in vivo appeared to deplete the population of infected neural progenitor cells that remain in the SVZ during early postnatal development.

In summary, our findings suggest that ATF5 acts to maintain neural progenitor cells in the cell cycle and negatively regulates their differentiation into neurons and glia. ATF5 expression is subject to downregulation by growth factors that also convey instructive signals regarding neural progenitor cell differentiation. However, levels of ATF5 expression may affect neural pro- genitor cell properties. Perturbation of ATF5 expression or function has significant effects on progenitor differentiation in vitro and in vivo. Such findings reinforce the conclusion that ATF5 is a major element in the mechanism by which the timing of neural progenitor proliferation and differentiation are regulated.

\section{References}

Angelastro JM, Klimaschewski L, Tang S, Vitolo OV, Weissman TA, Donlin LT, Shelanski ML, Greene LA (2000) Identification of diverse nerve growth factor-regulated genes by serial analysis of gene expression (SAGE) profiling. Proc Natl Acad Sci USA 97:10424-10429.

Angelastro JM, Ignatova TN, Kukekov VG, Steindler DA, Stengren GB, Mendelsohn C, Greene LA (2003) Regulated expression of ATF5 is required for the progression of neural progenitor cells to neurons. J Neurosci 23:4590-4600.

Arlotta P, Magavi SS, Macklis JD (2003) Induction of adult neurogenesis: molecular manipulation of neural precursors in situ. Ann NY Acad Sci 991:229-236.

Barnabe-Heider F, Miller FD (2003) Endogenously produced neurotrophins regulate survival and differentiation of cortical progenitors via distinct signaling pathways. J Neurosci 23:5149-5160.

Bylund M, Andersson E, Novitch BG, Muhr J (2003) Vertebrate neurogenesis is counteracted by Sox1-3 activity. Nat Neurosci 6:1162-1168.

Chenn A, Walsh CA (2002) Regulation of cerebral cortical size by control of cell cycle exit in neural precursors. Science 297:365-369.

Chenn A, Walsh CA (2003) Increased neuronal production, enlarged forebrains and cytoarchitectural distortions in beta-catenin overexpressing transgenic mice. Cereb Cortex 13:599-606.

Eliasson C, Sahlgren C, Berthold CH, Stakeberg J, Celis JE, Betsholtz C, Eriksson JE, Pekny M (1999) Intermediate filament protein partnership in astrocytes. J Biol Chem 274:23996-24006.

Filippov V, Kronenberg G, Pivneva T, Reuter K, Steiner B, Wang LP, Yamaguchi M, Kettenmann H, Kempermann G (2003) Subpopulation of nestin-expressing progenitor cells in the adult murine hippocampus shows electrophysiological and morphological characteristics of astrocytes. Mol Cell Neurosci 23:373-382.

Gage FH (2000) Mammalian neural stem cells. Science 287:1433-1438.

Graham V, Khudyakov J, Ellis P, Pevny L (2003) SOX2 functions to maintain neural progenitor identity. Neuron 39:749-765.

Imura T, Kornblum HI, Sofroniew MV (2003) The predominant neural stem cell isolated from postnatal and adult forebrain but not early embryonic forebrain expresses GFAP. J Neurosci 23:2824-2832.

Jacobsen CT, Miller RH (2003) Control of astrocyte migration in the developing cerebral cortex. Dev Neurosci 25:207-216.

Kakita A, Goldman JE (1999) Patterns and dynamics of SVZ cell migration in the postnatal forebrain: monitoring living progenitors in slice preparations. Neuron 23:461-472.

Kintner C (2002) Neurogenesis in embryos and in adult neural stem cells. J Neurosci 22:639-643.

Kukekov VG, Laywell ED, Thomas LB, Steindler DA (1997) A nestinnegative precursor cell from the adult mouse brain gives rise to neurons and glia. Glia 21:399-407.

Kukekov VG, Laywell ED, Suslov O, Davies K, Scheffler B, Thomas LB, O’Brien TF, Kusakabe M, Steindler DA (1999) Multipotent stem/progenitor cells with similar properties arise from two neurogenic regions of adult human brain. Exp Neurol 156:333-344.

Laywell ED, Kukekov VG, Steindler DA (1999) Multipotent neurospheres can be derived from forebrain subependymal zone and spinal cord of adult mice after protracted postmortem intervals. Exp Neurol 156:430-433.

Laywell ED, Rakic P, Kukekov VG, Holland EC, Steindler DA (2000) Identification of a multipotent astrocytic stem cell in the immature and adult mouse brain. Proc Natl Acad Sci USA 97:13883-13888.

Laywell ED, Kukekov VG, Suslov O, Zheng T, Steindler DA (2002) Production and analysis of neurospheres from acutely dissociated and postmortem CNS specimens. Methods Mol Biol 198:15-27.

Levison SW, Chuang C, Abramson BJ, Goldman JE (1993) The migrational patterns and developmental fates of glial precursors in the rat subventricular zone are temporally regulated. Development 119:611-622.

Li W, Cogswell CA, LoTurco JJ (1998) Neuronal differentiation of precursors in the neocortical ventricular zone is triggered by BMP. J Neurosci 18:8853-8862. 
Marshall CA, Goldman JE (2002) Subpallial dlx2-expressing cells give rise to astrocytes and oligodendrocytes in the cerebral cortex and white matter. J Neurosci 22:9821-9830.

Marshall CA, Suzuki SO, Goldman JE (2003) Gliogenic and neurogenic progenitors of the subventricular zone: who are they, where did they come from, and where are they going? Glia 43:52-61.

Mason JL, Goldman JE (2002) A2B5+ and O4+ cycling progenitors in the adult forebrain white matter respond differentially to PDGF-AA, FGF-2, and IGF-1. Mol Cell Neurosci 20:30-42.

Mason JL, Angelastro JM, Ignatova TN, Kukekov VG, Lin G, Greene LA, Goldman JE (2005) ATF5 regulates the proliferation and differentiation of oligodendrocytes. Mol Cell Neurosci, in press.

Mehler MF (2002) Mechanisms regulating lineage diversity during mammalian cerebral cortical neurogenesis and gliogenesis. Results Probl Cell Differ 39:27-52.

Menard C, Hein P, Paquin A, Savelson A, Yang XM, Lederfein D, BarnabeHeider F, Mir AA, Sterneck E, Peterson AC, Johnson PF, Vinson C, Miller FD (2002) An essential role for a MEK-C/EBP pathway during growth factor-regulated cortical neurogenesis. Neuron 36:597-610.

Noctor SC, Flint AC, Weissman TA, Wong WS, Clinton BK, Kriegstein AR (2002) Dividing precursor cells of the embryonic cortical ventricular zone have morphological and molecular characteristics of radial glia. J Neurosci 22:3161-3173.

Noctor SC, Martinez-Cerdeno V, Ivic L, Kriegstein AR (2004) Cortical neurons arise in symmetric and asymmetric division zones and migrate through specific phases. Nat Neurosci 7:136-144.

Palmer TD, Markakis EA, Willhoite AR, Safar F, Gage FH (1999) Fibroblast growth factor- 2 activates a latent neurogenic program in neural stem cells from diverse regions of the adult CNS. J Neurosci 19:8487-8497.

Park JK, Williams BP, Alberta JA, Stiles CD (1999) Bipotent cortical progenitor cells process conflicting cues for neurons and glia in a hierarchical manner. J Neurosci 19:10383-10389.

Qian X, Shen Q, Goderie SK, He W, Capela A, Davis AA, Temple S (2000) Timing of CNS cell generation: a programmed sequence of neuron and glial cell production from isolated murine cortical stem cells. Neuron 28:69-80.

Schmidt-Kastner R, Humpel C (2002) Nestin expression persists in astrocytes of organotypic slice cultures from rat cortex. Int J Dev Neurosci 20:29-38.

Schuurmans C, Guillemot F (2002) Molecular mechanisms underlying cell fate specification in the developing telencephalon. Curr Opin Neurobiol 12:26-34.

Sun Y, Nadal-Vicens M, Misono S, Lin MZ, Zubiaga A, Hua X, Fan G, Greenberg ME (2001) Neurogenin promotes neurogenesis and inhibits glial differentiation by independent mechanisms. Cell 104:365-376.

Suzuki SO, Goldman JE (2003) Multiple cell populations in the early postnatal subventricular zone take distinct migratory pathways: a dynamic study of glial and neuronal progenitor migration. J Neurosci 23:4240-4250.

Wei LC, Shi M, Chen LW, Cao R, Zhang P, Chan YS (2002) Nestincontaining cells express glial fibrillary acidic protein in the proliferative regions of central nervous system of postnatal developing and adult mice. Brain Res Dev Brain Res 139:9-17.

Zerlin M, Levison SW, Goldman JE (1995) Early patterns of migration, morphogenesis, and intermediate filament expression of subventricular zone cells in the postnatal rat forebrain. J Neurosci 15:7238-7249. 